\title{
Dorota SZYMANIUK
}

Uniwersytet w Białymstoku

\section{Z BADAŃ PORÓWNAWCZYCH NAD INTONACJĄ W JEZZYKU ANGIELSKIM I ROSYJSKIM}

Niniejszy artykuł posiada strukturę dwudzielną. Zgodnie $\mathrm{z}$ intencją autorki w jego pierwszej, zasadniczej części omówiono problematykę lingwistycznych studiów konfrontatywnych nad angielską i rosyjską intonacją. Część drugą poświęcono prezentacji wstępnych wyników eksperymentu, którego celem jest charakterystyka przebiegu melodii $w$ angielskich i rosyjskich zdaniach wyrażających entuzjazm i irytację.

W dorobku studiów porównawczych obejmujących wymienione języki badania nad intonacją mają dość ugruntowaną pozycję i znaczne osiągnięcia. Znakomita część prac traktuje omawiane zagadnienie albo $\mathrm{z}$ perspektywy istniejących $\mathrm{w}$ obu systemach uniwersalnych cech melodii mowy i różnic formalno-funkcjonalnych, albo przez pryzmat intonacji języka rosyjskiego jako źródła interferencji w mowie Rosjan posługujących się językiem angielskim jako obcym (Svetozarova 1998). Komparacja obu systemów w kierunku przeciwnym, tzn. wychodząc od języka angielskiego jako czynnika transferu negatywnego w języku rosyjskim osób anglojęzycznych, oprócz ogólnych omówień w kilku poradnikach i kursach fonetyki rosyjskiej (por. Matthews 1969; Lubensky and Jarvis 1984; Bolinger 1989; Keijsper 1992; Trofimov et. al 2002), znajduje się praktycznie poza polem zainteresowania.

Niezależnie od dyskusji i sporów na temat właściwości angielskiej i rosyjskiej intonacji oraz stosowanych metod porównawczych, za oczywisty fakt przyjmuje się obecność $\mathrm{w}$ podsystemie tonalnym omawianych języków dwóch stojących względem siebie w opozycji tonów podstawowych - kadencji i antykadencji (Miatluk 1986). Wątpliwości nie budzą również podobieństwa funkcjonalne, a więc sposób i zakres wykorzysta- 
nia środków intonacyjnych, np. zmiana wysokości tonu służy wprowadzeniu nowych treści, ton opadający wskazuje na wypowiedź zamkniętą, zakończoną, antykadencja zdaniowa informuje, iż wypowiedź wymaga uzupełnienia, odpowiedzi czy wyjaśnienia.

W pierwszych próbach typologii angielskiej i rosyjskiej intonacji opartych na wypowiedziach neutralnych (Leed 1965; Arakina 1989; Cubberley, 2002) wyróżniono następujące kategorie grup intonacyjnych ${ }^{1}$ :

1. Opadający korpus i opadający odcinek terminalny - w zdaniach rozkazujących, wykrzyknikowych, pytających z wyrazem pytającym (w obu językach poziom tonu rośnie na wyrazie pytającym) i oznajmujących, np.:

'This 'subject is \difficult.

'Он 'часто гу'^яет в \парке.
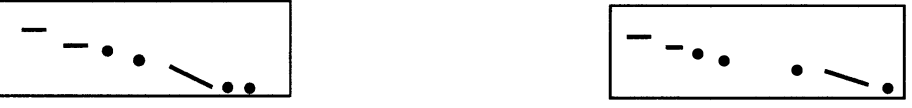

2. Opadający korpus i rosnący odcinek terminalny - w zdaniach wymagających uzupełnienia, zdaniach podrzędnych poprzedzających zdanie nadrzędne i w pytaniach ogólnych, np.:

'Is it a $\nearrow$ motorbike?

'Это 'твой ГАом?
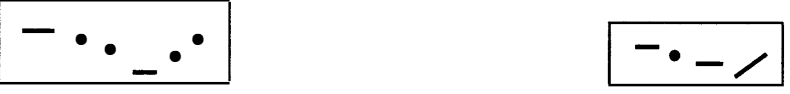

1 Niezbędnym działaniem poprzedzającym badanie systemów intonacyjnych jest ustalenie jednostki minimalnej, podstawowej, w ramach której realizowana jest melodia. W intonologii wciąż panuje różnorodność terminologiczna - jednostką tą jest grupa znaczeniowa (sense-group), grupa oddechowa (breath-group), grupa tonalna (tone group), wzorzec akcentowy (stress pattern), konstrukcja intonacyjna, zestrój intonacyjny, fraza intonacyjna, itp. $\mathrm{W}$ najnowszych publikacjach najczęściej stosowanym terminem jest fraza intonacyjna. W niniejszym artykule będę posługiwać się zamiennie pojęciem frazy intonacyjnej i grupy intonacyjnej. W grupie intonacyjnej wyróżniam korpus (odcinek przed sylabą nuklearną) i odcinek terminalny (sylaba nuklearna + pozostałe sylaby następujące po sylabie nuklearnej). Ponadto, $\mathrm{w}$ prezentowanych przykładach zastosowałam wywodzącą się $\mathrm{z}$ tradycji brytyjskiej pozatekstową transkrypcję suprasegmentalną, w której między liniami poziomymi wyznaczającymi górną i dolną granicę głosu zastosowano następujące symbole graficzne: dla oznaczenia sylaby akcentowanej - kreska, dla oznaczenia sylaby nieakcentowanej - kropka. 
3. Opadający korpus i równy odcinek terminalny - w zdania wtrąconych, np.:

The 'country as you, know is \rich.

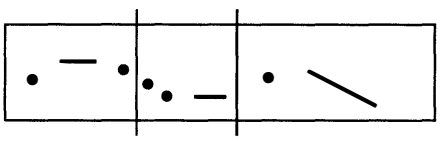

'Он на'сколько я, знаю жи'вёт в \Мондоне.

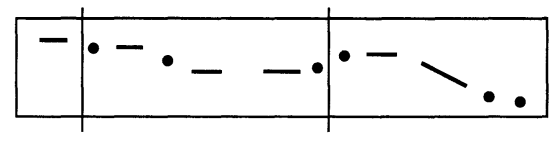

W powyższych typach fraz zmiana wysokości tonu rozpoczyna się od poziomu średniego, a spadek realizowany jest na każdej kolejnej sylabie akcentowanej.

Obok elementów wspólnych autorzy klasyfikacji porównawczych wskazują na typowe cechy melodii rosyjskich grup intonacyjnych, do których należą:

1. Rosnący korpus i rosnący odcinek terminalny, np.

Хо'тите Лкофе?

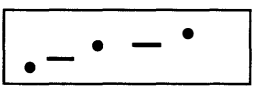

2. Rosnący korpus i opadający odcinek terminalny, np.

Ко'гда 'он при Једет?

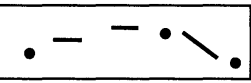

Jak widać, rodzimi użytkownicy języka rosyjskiego, posługując się językiem angielskim jako obcym, mogą popełniać błędy intonacyjne. Okazuje się bowiem, że $\mathrm{w}$ języku rosyjskim wypowiedzi neutralne realizowane są z wykorzystaniem bogatszej gamy tonów. Dodatkowo, $\mathrm{w}$ przypadkach, gdy zarówno $\mathrm{w}$ języku angielskim, jak i w języku rosyjskim realizacja jednakowych typów wypowiedzi (oznajmujących, pytających, itd.) wymaga zastosowania takich samych środków intonacyjnych (opadający korpus + opadający, rosnący lub równy ton ter- 
minalny), w angielskich wypowiedziach Rosjan dadzą się prawdopodobnie zaobserwować różnice formalne związane z jakościową modyfikacją tonu w poszczególnych odcinkach frazy. Stanowią one źródło istotnych kontrastów intonacyjnych między omawianymi językami. Dlatego też klasycy angielsko-rosyjskiej intonologii porównawczej skupiają uwagę na: 1) opisie realizacji wszystkich typów tonów terminalnych odbiegających od normy, 2) charakterystyce struktury intonacyjnej poszczególnych kategorii zdaniowych, 3) analizie sposobów realizacji korpusu opadającego, terminalnego tonu opadającego i terminalnego tonu rosnącego.

Poważna część badań porównawczych należy do Torsujewa (1956: 148), który już ponad pół wieku temu podkreślał, że w opadającej linii melodycznej zdania rosyjskiego brak jest typowego dla intonacji angielskiej stopniowego i regularnego przechodzenia sylab z poziomu wyższego na poziom niższy. $W$ języku rosyjskim sylaby nieakcentowane między akcentowanymi wymawia się nieco wyżej niż poprzedzające je akcentowane, a więc spadek następuje skokowo, np.:

'This is a 'nice \house. 'Это кра'сивый \дом.
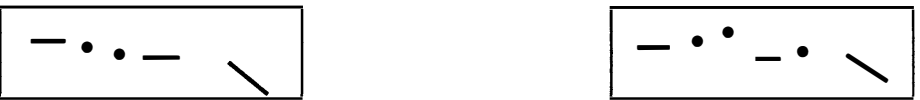

Berlin i Weichman (1973: 34-35) dodają, że pierwsza sylaba akcentowana $\mathrm{w}$ angielskiej frazie intonacyjnej charakteryzuje się najwyższym poziomem tonu w porównaniu do pozostałych sylab korpusu, natomiast w rosyjskim korpusie takiej prawidłowości nie obserwuje się - pierwsza sylaba akcentowana nie musi być wyższa od innych następujących po niej sylab akcentowanych np.:

To'morrow we will 'go for a \walk.



'Завтра пой'дём на про \гулку.

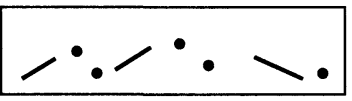


W przeciwieństwie do języka rosyjskiego, w języku angielskim terminalny ton opadający charakteryzuje się ostrym obniżeniem, które sięga wartości minimalnych (por. przykłady wyżej). Terminalny ton rosnący $\mathrm{w}$ angielskich grupach intonacyjnych posiada niższy $\mathrm{w}$ porównaniu do języka rosyjskiego początkowy poziomem wzrostu, krzywa rosnąca ma rysunek łagodniejszy, a wzrost tonu nie przekracza poziomu pierwszej sylaby akcentowanej w grupie intonacyjnej, np.:

'Are you 'going to $\nearrow$ help me? 'Ты 'мне по
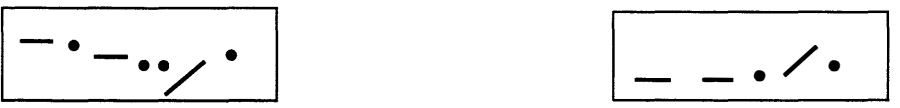

W sytuacji, gdy wzrost tonu odbywa się na sylabach nieakcentowanych odcinka terminalnego, $\mathrm{w}$ języku angielskim ostatnia sylaba akcentowana znajduje się na najniższym możliwym poziomie, a następujące po niej nieakcentowane są nośnikiem wzrostu. W języku rosyjskim natomiast wzrost następuje na przestrzeni ostatniej sylaby akcentowanej, po której nieakcentowane ulegają obniżeniu [op. cit.: 38-39], np.:

'Does he 'speak $\nearrow$ Polish?

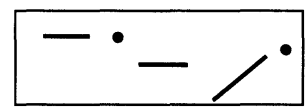

'Он гово'рит по- польски?

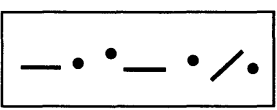

Badania empiryczne pozwoliły określić typowe naruszenia angielskiej normy intonacyjnej $\mathrm{w}$ angielskich wypowiedziach Rosjan. W tym miejscu należy przypomnieć, że prowadzone analizy porównawcze opierały się wyłącznie na wariantach normatywnych: brytyjskiej odmianie języka angielskiego, tzw. RP (Received Pronounciation), i rosyjskim języku literackim. Ich wybór został podyktowany co najmniej dwoma względami: po pierwsze, oba warianty zostały opisane $w$ literaturze $w$ możliwie wyczerpujący sposób, po drugie, $\mathrm{z}$ racji powszechnego stosowania jako odmian nauczanych, są najbardziej podatne na działanie interferencji.

Przywoływany powyżej Torsujew (1956), a za nim Wiszniewskaja (1985) i Miatluk (1986) wskazali liczne przykłady zachwiania normy intonacyjnej $\mathrm{w}$ angielskich wypowiedziach Rosjan. W trakcie realizacji poszczególnych tonów zaobserwowano szereg modyfikacji, które prezentuję poniżej: 
Niski ton opadający:

1. zbyt wąski interwał zmiany tonu - zdanie percypowane jest jako wymagające uzupełnienia,

2. poziom tonu sylaby nuklearnej nie osiąga dolnej granicy diapazonu. Niski ton rosnący:

1. ostre (rysunek krzywej) podwyższenie tonu,

2. zbyt wysoki wzrost tonu na sylabach nieakcentowanych w odcinku terminalnym, który sięga powyżej poziomu pierwszej sylaby akcentowanej korpusu,

Wysoki ton opadający:

1. zwężenie diapazonu,

2. ostry rysunek krzywej spadku.

\section{Wysoki ton rosnący:}

1. ostry rysunek krzywej wzrostu.

\section{Ton opadająco-rosnący:}

1. zastępowanie $\mathrm{w} / \mathrm{w}$ tonu prostym tonem rosnącym,

2. komponent opadający rozpoczyna się na średnim tonie i kończy podwyższonym, a komponent rosnący - na średnim lub wysokim (normatywny angielski ton opadająco-rosnący to wysoki poziom początkowy i niski poziom końcowy spadku oraz niski poziom początkowy wzrostu).

\section{Ton rosnąco-opadający:}

1. ostry wzrost i spadek.

\section{Ton rosnąco-opadająco-rosnący:}

1. ten typ tonu nie występuje w angielskich wypowiedziach Rosjan.

Punktem wyjścia dla rozważań nad angielsko-rosyjską intonacją porównawczą mogą być również, co zostało zasygnalizowane wyżej, sposoby realizacji wybranych kategorii zdaniowych (oznajmujących, pytających, rozkazujących). Dlatego nie można pominąć zabiegów, w których dokonuje się porównania omawianych systemów przez pryzmat przyporządkowania określonej struktury przebiegu melodii do danej kategorii zdaniowej. Tabela poniżej, w której dokonano przeglądu wymienionych struktur, została sporządzona w oparciu o dostępne klasyfikacje (Kingdon 1958; O’Connor, Arnold 1967; Jassem 1973; Torsujeva 1974; Nikolajeva 1977; Bryzgunova 1977; Gimson 1989).

W języku angielskim i rosyjskim takie same typy tonów występują $\mathrm{w}$ prostych zdaniach twierdzących, pytaniach szczegółowych, pytaniach ogólnych i zdaniach rozkazujących. Istotne różnice dotyczą pozo- 
Tabela 1.

Struktura melodii w wybranych kategoriach zdaniowych w języku angielskim i rosyjskim

\begin{tabular}{|c|c|c|}
\hline Kategoria zdaniowa & Język angielski & Język rosyjski \\
\hline $\begin{array}{l}\text { Zdanie oznajmujące } \\
\text { zakończone }\end{array}$ & $\begin{array}{l}\text { Niski ton opadający } \\
\text { She 'bought two } \searrow \text { books }\end{array}$ & $\begin{array}{l}\text { IK - } 1 \text { (ton opadający) } \\
\text { Она купила Аве қнипи. }\end{array}$ \\
\hline \begin{tabular}{|l|}
$\begin{array}{l}\text { Zdanie oznajmujące } \\
\text { wymagające uzupełnienia }\end{array}$ \\
\end{tabular} & $\begin{array}{l}\text { Niski ton rosnący } \\
\text { 'Every } \nearrow \text { night he is \busy. }\end{array}$ & $\begin{array}{l}\text { IK - 3, 4, } 6 \text { (ton rosnący) } \\
\text { Каждый вечер (3) он занимается (1). }\end{array}$ \\
\hline Pytanie ogólne & $\begin{array}{l}\text { Niski ton rosnący } \\
\text { 'Can you } \nearrow \text { help? }\end{array}$ & $\begin{array}{l}\text { IK - } 3 \text { (ton rosnący) } \\
\text { Можете помочь? }\end{array}$ \\
\hline Pytanie szczegółowe & $\begin{array}{l}\text { Niski ton opadający } \\
\text { 'Where did you 'watch this \film? }\end{array}$ & $\begin{array}{l}\text { IK - } 2 \text { (ton opadający) } \\
\text { ГАе вы смотрели этот фимьм? }\end{array}$ \\
\hline Zdanie wykrzyknikowe & 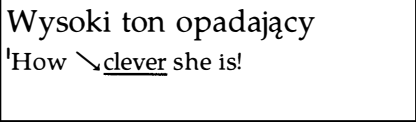 & $\begin{array}{l}\text { IK - } 5 \text { (ton rosnąco-opadający), } \\
6 \text { (ton rosnący) } \\
\text { Какая она умница! }\end{array}$ \\
\hline Rozkaz & 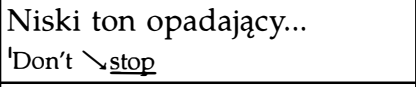 & $\begin{array}{l}\text { IK - } 2 \text { (ton opadający) } \\
\text { Не захерживайтесь! }\end{array}$ \\
\hline Prośba & $\begin{array}{l}\text { Niski ton rosnący lub } \\
\text { opadająco-rosnący } \\
\text { \Go to the } \nearrow \text { library. } \\
\end{array}$ & $\begin{array}{l}\text { IK - } 3 \text { (ton rosnąco-opadający) } \\
\text { Сходи, пожалуйста, в библиотеку. }\end{array}$ \\
\hline Zdanie wyliczające & $\begin{array}{l}\text { Niski ton rosnący }+ \text { wysoki } \\
\text { ton opadający } \\
\text { I 'bought some } \nearrow \text { meat, some } \nearrow \text { milk } \\
\text { and some } \searrow \text { bread. }\end{array}$ & $\begin{array}{l}\text { IK - } 6 \text { (ton rosnący) } \\
\text { Я купияа мяясо, молоко ㅆеб. }\end{array}$ \\
\hline
\end{tabular}

stałych typów zdań zarówno w podstawowej strukturze linii melodycznej (por. zdanie wykrzyknikowe), jak i jej szczegółowych modyfikacjach (por. $\mathrm{w}$ zdaniach angielskich opis kierunku tonu uzupełniony został o cechy konfiguracyjne, np. ton niski, ton wysoki).

Z powyższych ustaleń wynika, że:

- mimo wielu różnic formalnych funkcje intonacji w języku angielskim i rosyjskim są zbieżne,

- źródeł zjawisk interferencyjnych należy szukać zarówno w podobieństwach, jak i w różnicach strukturalnych przebiegu melodii (w tym konkretnym wypadku transfer negatywny dotyczy angielskich wypowiedzi Rosjan),

- prowadzona komparacja angielskiej i rosyjskiej intonacji uwzględniała przede wszystkim wypowiedzi neutralne emocjonalnie.

Powyższe wnioski oraz przegląd niezbyt obszernej literatury na temat prozodycznych wykładników emocji w aspekcie porównawczym, 
skłoniły mnie do bliższego przyjrzenia się strukturze melodii wypowiedzi emocjonalnych $\mathrm{w}$ języku angielskim i w języku rosyjskim. $\mathrm{W}$ trakcie gromadzenia materiału badawczego szczególną uwagę zwracałam na dialogi, w których ich uczestnicy w zależności od tematu dyskusji wyrażali swój entuzjazm lub irytację. Zasadnicza analiza percepcyjna i instrumentalna objęła 60 zdań ( $30 \mathrm{w}$ języku angielskim i $30 \mathrm{w}$ języku rosyjskim). Teksty poddano opracowaniu cyfrowemu i zapisano $\mathrm{w}$ postaci oscylogramów i intonogramów. W akustycznej części eksperymentu wykorzystano oprogramowanie PRAAT (http://www.fon.hum.uva.nl/praat/), które umożliwiło dokładne pomiary takich parametrów melodii korpusu i odcinka terminalnego frazy intonacyjnej jak poziom tonu, zakres tonu (diapazon) i kierunek zmian częstotliwości podstawowej. Otrzymane dane pomiarów i percepcji prezentuje tabela poniżej.

Tabela 2.

\section{Cechy melodii zdań wyrażających entuzjazm i irytację $w$ języku angielskim i rosyjskim}

\begin{tabular}{|c|c|c|c|c|}
\hline & \multicolumn{2}{|c|}{ Język angielski } & \multicolumn{2}{|c|}{ Język rosyjski } \\
\hline & Entuzjazm & Irytacja & Entuzjazm & Irytacja \\
\hline $\begin{array}{l}\text { Kierunek zmian krzywej } \\
\text { korpusu }\end{array}$ & Opadający & Opadający & Opadający & Opadający \\
\hline $\begin{array}{l}\text { Średni poziom tonu } \\
\text { w korpusie }(\mathrm{Hz})\end{array}$ & 377 & 460 & 408 & 459 \\
\hline Diapazon korpusu (Hz) & $\begin{array}{l}\text { Wąski }(\sim 148) \\
\text { Średni }(\sim 213) \\
\text { Szeroki }(\sim 300)\end{array}$ & Średni $(\sim 264)$ & Średni $(\sim 243)$ & $\begin{array}{l}\text { Wąski }(\sim 120) \\
\text { Średni }(\sim 217) \\
\text { Szeroki }(\sim 310)\end{array}$ \\
\hline $\begin{array}{l}\text { Kierunek zmian krzywej } \\
\text { tonu terminalnego }\end{array}$ & $\begin{array}{l}\text { Opadający, } \\
\text { Rosnąco- } \\
\text {-opadający, }\end{array}$ & $\begin{array}{l}\text { Opadający, } \\
\text { Rosnąco- } \\
\text {-opadający, } \\
\text { Opadająco- } \\
\text {-rosnący }\end{array}$ & Opadający & Opadający \\
\hline $\begin{array}{l}\text { Średni poziom tonu } \\
\text { terminalnego }(\mathrm{Hz})\end{array}$ & 274 & 418 & 308 & 247 \\
\hline $\begin{array}{l}\text { Kształt krzywej opadania } \\
\text { tonu terminalnego }\end{array}$ & Spadek łagodny & $\begin{array}{l}\text { Spadek ostry, } \\
\text { Spadek łagodny }\end{array}$ & $\begin{array}{l}\text { Spadek ostry, } \\
\text { Spadek lagodny }\end{array}$ & $\begin{array}{l}\text { Spadek ostry, } \\
\text { Spadek łagodny }\end{array}$ \\
\hline
\end{tabular}

Zaobserwowane podobieństwa cech intonacji angielskich i rosyjskich zdań wyrażających entuzjazm i irytację dotyczą: 1) wysokiego po- 
ziomu tonu frazy intonacyjnej, 2) dominacji opadającego kierunku tonu zarówno w korpusie, jak i w odcinku terminalnym, 3) ostrego lub łagodnego rysunku przebiegu krzywej kadencyjnej.

Większość analizowanych parametrów intonacji jest rozbieżna. Intonacja entuzjazmu $\mathrm{w}$ angielskich i rosyjskich frazach wykazuje różnice odnośnie diapazonu korpusu i typów krzywej tonu terminalnego. W wypowiedziach angielskich odnotowano diapazon wąski (40\%), średni $(20 \%)$ i szeroki $(40 \%)$, podczas gdy $\mathrm{w}$ wypowiedziach rosyjskich $100 \%$ badanych korpusów charakteryzowało się diapazonem średnim. Na przykład intonogram zdania А тут сюрприз! (Rys. 1) prezentuje średni diapazon i łagodną krzywą tonu terminalnego, a intonogram zdania Все живы здоровы! (Rys. 2) średni diapazon i ostrą krzywą tonu terminalnego.

Rys. 1.

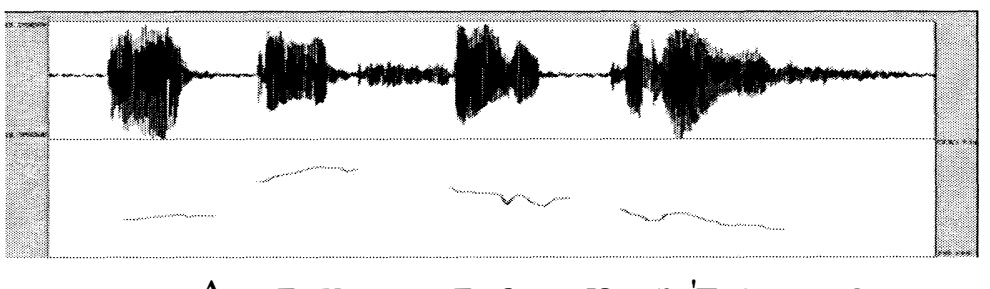

А

Rys. 2.

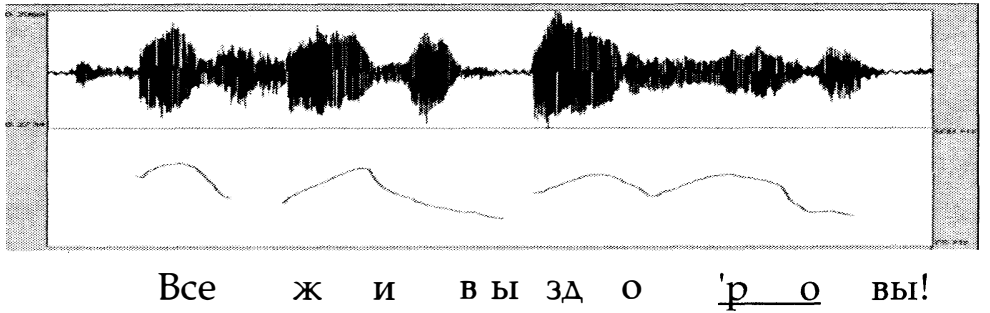

Frazę angielską wyrażającą entuzjazm wymawiano z opadającym tonem terminalnym $(80 \%)$ i $z$ tonem rosnąco-opadającym (20\%). Różnice między językami w rysunku krzywej tonu terminalnego dotyczyły wartości interwału kadencji przy zbliżonym średnim czasie zachodzących zmian, na przykład we frazach rosyjskich $\mathrm{w}$ przedziale 0,495 s. odnotowano interwały $65 \mathrm{~Hz}$ (por. rys. 1) i $173 \mathrm{~Hz}$ (por. rys. 2), a we frazach angielskich przy czasie około 0,431 s. zaobserwowano regularną zmianę o około $153 \mathrm{~Hz}$ (por. rys. 3). 
Rys. 3.

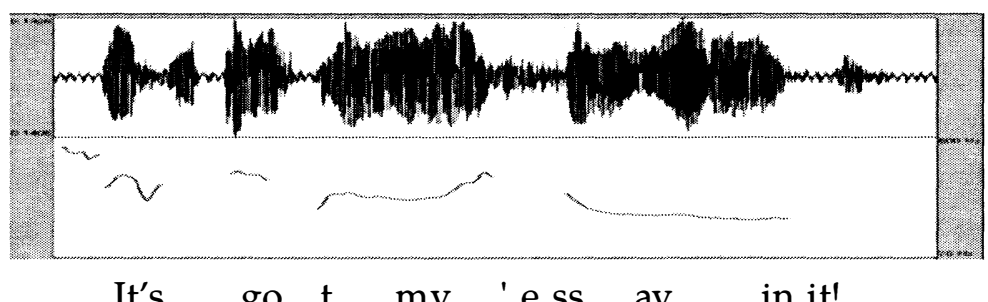

It's go $t$ my 'ess ay in it!

Różnice cech melodii w zdaniach wyrażających irytację dotyczą głównie odcinka terminalnego. $W$ przedziale średnich wartości początkowego poziomu kadencji ustalono dla języka angielskiego ok. $418 \mathrm{~Hz}$, a dla języka rosyjskiego ok. 247Hz. W obu językach kadencja może przebiegać łagodnie i ostro, $z$ tym, że $w$ języku rosyjskim - podobnie jak w intonacji entuzjazmu - różnice interwału $(50 \mathrm{~Hz}, 110 \mathrm{~Hz})$ przy zbliżonym czasie trwania zmian $(0,64$ s.) dały $75 \%$ krzywych łagodnych i $25 \%$ krzywych ostrych. $\mathrm{W}$ angielskiej intonacji zdań wyrażających irytację $\mathrm{w}$ podobnym czasie, tj. 0,63 s., były realizowane interwały szersze $(162 \mathrm{~Hz}, 260 \mathrm{~Hz})$. Ponadto we frazach rosyjskich wystąpiły przypadki kadencji z interwałem $110 \mathrm{~Hz}$ w ciągu 0,32 s., co w sposób zasadniczy modyfikowało rysunek krzywej przebiegu tonu.

Porównanie wartości diapazonu pokazuje, że $100 \%$ angielskich korpusów posiada średnie wartości diapazonu, podczas gdy w korpusach rosyjskich występują wszystkie typy diapazonów.

W zdaniach angielskich oprócz prostych (opadających) tonów terminalnych, mamy także tony złożone rosnąco-opadające i opadająco-rosnące realizowane zarówno na przestrzeni sylaby nuklearnej, jak i całego odcinka terminalnego (por. rys. 4).

Rys. 4.

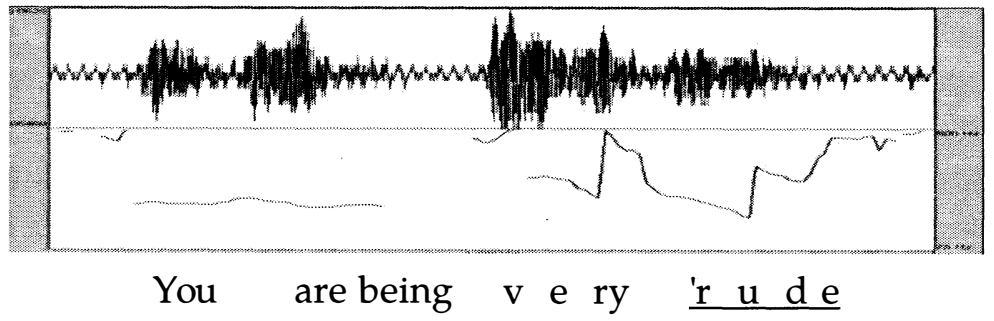

Powyższe ustalenia, choć jeszcze niepełne, potwierdzają obecność $\mathrm{w}$ angielskich i rosyjskich zdaniach emocjonalnych wspólnych i językowo 
specyficznych cech melodii. Wciąż jednak nie można mówić o intonacji entuzjazmu czy irytacji głównie ze względu na wąski zakres zjawisk prozodycznych (struktura melodii) poddanych analizie.

\section{BIBLIOGRAFIA}

Bolinger, D. 1989. Intonation and its uses. Stanford University Press.

O'Connor, J. D., Arnold, G. F.1967. Intonation of Colloquial English. A Practical Handbook. Longmans.

Crystal, D. 1995. The Cambridge Encyclopedia of the English Language. Cambridge: Cambridge University Press.

Cubberley, P. V. 2002. Russian. A Linguistic Introduction. Cambridge: Cambridge University Press.

Gimson, A. C. 1989. An Introduction to the Pronunciation of English. London: Edward Arnold.

Holden, K. T. 1993. "The emotive impact of foreign intonation. An experiment in switching English and Russian intonation", Language and Speech 36, 67-88.

Jassem, W. 1973. Podręcznik wymowy angielskiej. Warszawa: Wydawnictwo Naukowe PWN.

Keijsper, C. E. 1992. Recent intonation research and its implications for teaching Russian, Studies in Russian Linguistics Vol. 15, Amsterdam: RODOPI, 151-214.

Kingdon, R. 1958. The Groundwork of English Intonation. Longmans.

Leed, R. 1965. "A contrastive analysis of Russian and English intonation contours" Journal of Social Issues 23, 91-108.

Leontieva, S. F. 1980. A Theoretical Course of English Phonetics. Moscow.

Lubensky, S., Jarvis, D. K. 1984. Teaching, learning, acquiring Russian. Slavica Publishers.

Matthews, W. K. 1969. The Structure and Development of Russian. Cambridge: Cambridge University Press.

Svetozarova, N. D. 1998. Intonation in Russian, [w:] Hirst, D., Di Cristo, A. (eds.), Intonation Systems, Cambridge: Cambridge University Press, 261-274.

Trofimov, M. V., Jones, D., Collins, B., Mees, M. I. 2002. European Languages II: Russian, Routledge.

Аракин, В. А. 1989. Справнительная типология английского и русского языков. Москва.

Берлин, С. А., Вейхман, А. С. 1973. Обяуиение английской интонащии. Москва. Брызгунова, Е. А. 1977. Звуки и и интонация русской речи. Москва.

Вншневская, Г. М. 1985. Английская интонаиия (в условиях русской интерферениии). Учебное пособие. Иваново.

Метлюк, А. А. 1986. Взаимодействие просодических систем в речи билингва. Минск. 
Николаева, Т. М. 1977. Фразовая интонащия славянских языков. Москва. Торсуев, Г. П. 1956. Обуиение английскому произношению. Москва. Торсуева, И. Г. 1974. Теория интонаиии. Москва.

\section{CONTRASTIVE STUDIES ON INTONATION IN ENGLISH AND RUSSIAN}

\section{Summary}

The article consists of two parts. In the first part the issues connected with English-Russian contrastive studies on intonation are discussed. In the second one the results of the perceptual-acoustic experiment on the melodic structure of English and Russian utterances expressing enthusiasm and irritation are presented. 